\title{
Exergoeconomic Analysis and Optimization of a Novel Isobaric Adiabatic Compressed Air Energy Storage System
}

\author{
Y. Mazloum*, H. Sayah, M. Nemer \\ MINES ParisTech, PSL - Research University, CES - Center for Energy efficiency of Systems (CES), Z.I. Les Glaises - 5 \\ rue Léon Blum 91120 Palaiseau, France \\ E-mail: *youssef.mazloum07@gmail.com
}

Received 21 September 2016, Revised 04 December 2016, Accepted 03 January 2017

\begin{abstract}
The contribution of the renewable energy sources in the electricity generation mix is greatly increasing. Nonetheless, the intermittence of these sources breaks the balance between supply and demand for electricity. Thus, the integration of the energy storage technologies with the electrical grid is becoming crucial to restore this balance. Hence, this paper discusses the modeling of a novel isobaric adiabatic compressed air energy storage (IA-CAES) system. This system is characterized by the recovery of the compression heat and the storage of the compressed air under fixed pressure in hydro-pneumatic tanks. This allows the improvement of the efficiency of the storage system. A steady state model is then developed to perform energy and exergy analyses of the IA-CAES system. An exergoeconomic model is also carried out in order to optimize the cost-effectiveness of the storage system by using a genetic algorithm. The system efficiency is $55.1 \%$ in the base case, it is improved to $56.6 \%$ after optimization with a decrease in the capital investment by $5.6 \%$. Global sensitivity analyses are finally carried out to estimate the effects of some key parameters on the system's cost-effectiveness. They show that the system is mostly influenced by the isentropic efficiency of the air turbines.
\end{abstract}

Keywords: Efficiency; exergoeconomic analysis; isobaric adiabatic compressed air energy storage (IA-CAES) system; optimization; thermodynamic modeling.

\section{Introduction}

The balance between power generation and consumption is the major challenge in the grid operation. However, the enlarged penetration of the renewable energy sources into the electrical grid breaks this balance due to the intermittence nature of the renewable power sources. In fact, the global warming concerns call for increasing the contribution of renewable energy sources in the electricity production. Thus, energy storage systems are needed to manage the balance of the electrical grid by storing the electrical energy during offpeak load hours and releasing it back during peak load hours [1].

The pumped hydro storage (PHS) system and the compressed air energy storage (CAES) system are the only energy storage technologies with large energy storage capacity and power capacity. However, these systems have high capital costs and require suitable geological sites [2]. Then, this paper discusses the modeling and the exergoeconomic optimization of an innovative isobaric adiabatic compressed air energy storage (IA-CAES) system.

In the literature, many studies regarding the CAES systems have been conducted for improving the system efficiency ( $40 \%$ for the conventional CAES system [1]). The McIntosh plant integrates a recuperator to recover the waste heat from the turbine exhaust and preheat the compressed air before entering the combustion chamber. The fuel consumption is then reduced by $25 \%$ and the energy efficiency is improved by about $12 \%$ [3]. Saadat et al. [4] studied a CAES system where air is stored at a high fixed pressure in a dual chamber liquid-compressed air storage vessel. The storage pressure is kept fixed and the compression/expansion processes are achieved by an isothermal way in order to improve the efficiency which reaches $74.8 \%$. Safaei and Keityh [3] proposed a distributed CAES plant. In this case, the compressors are located near the concentrated heating loads in order to benefit from the wasted compression heat and thereby enhance the system efficiency. Nielsen and Leithner [5] designed an isobaric adiabatic CAES plant with a combined cycle. The compression heat is stored and reused to preheat air prior the combustion chamber during the production phase. Then, a brine shuttle pond is installed in this plant at the surface to maintain approximately a fixed pressure in the cavern and therefore to reduce the compressor losses. A steam cycle is also installed to recover the turbine exhaust heat. The net efficiency of the proposed system is about $65.76 \%$. Zhao et al. [6] proposed to integrate a Kalina cycle at the output of the low pressure turbine to recover the exhaust heat and improve the performance of the CAES system. The efficiency is improved up to $47.64 \%$. Mazloum et al. [7] analyzed an adiabatic CAES system without using a combustion chamber. The compression heat is stored during the storage phase as hot water and reused during the destocking phase to warm up the compressed air before its expansion in the turbines. The compression heat recovery increases the efficiency to $66 \%$.

The storage system developed in this paper is a combination between a CAES system with a thermal energy storage system and a PHS system. During the storage phase, the compression heat is recovered and stored as hot water in 
thermal storage tanks. During the production phase, the compressed air is heated by using the already stored hot water before each stage of expansion. Thus the combination with the thermal energy storage system avoids the use of fossil fuel sources and improves the efficiency of the system. Moreover, the combination with the PHS system allows maintaining a fixed storage pressure and operating the rotating machines under their optimal conditions in order to reduce the losses due to the storage pressure variations. Additionally, the compressed air is stored in this system in artificial tanks which permit to overcome the geological site limitations. Indeed, the compressed air is stored, in the conventional CAES systems, in underground caverns whose availability has limited the propagation of this technology. Energy and exergy analyses are carried out in this paper to study the thermodynamic characteristics of the IA-CAES system.

Furthermore, an exergoeconomic analysis of the innovative storage system is performed in order to find out an optimum solution for which the total cost given by the sum of the operating cost (efficiency) and the investment cost is minimum. The exergoeconomic principles have been usually applied to simple conventional energy conversion systems. To the extent of our knowledge, it is the first time that a CAES system is optimized by an exergoeconomic approach. The exergoeconomic analysis is a combination between the exergy analysis of a system and the economic studies represented by the investment cost and the fuel cost [8]. Among the existing exergoeconomic methods, the SPECO (specific exergy costing) method is selected to analyze the storage system. Lazzaretto and Tsatsaronis [9] proved that the cost rates calculated by the different exergoeconomic approaches are similar as much as the fuel and product definitions are the same. In addition, they demonstrated that the SPECO method is sufficient and summarizes all the previous approaches. It defines the fuel and the product of each component, and the auxiliary equations used to calculate either the average costs or the local average costs [10]. The exergoeconomic models have been used with various algorithms with the purpose of optimizing the considered system, such as the genetic algorithm which will be used in this paper [11]. The associated optimizer is called OmOptim, it is a software developed in our laboratory and allows optimizing specific parameters and objective functions using a genetic algorithm.

This paper is divided into 6 sections: first, the IA-CAES system is described in Section 2. Then, the thermodynamic modeling of each component of the storage system is presented in Section 3. After that, the exergoeconomic model is presented in section 4 . The results are explained in section 5. And finally, conclusions are drawn in Section 6.

\section{System Overview}

The proposed IA-CAES system is shown in Figure 1. This system consists of a compression train with inter cooling, an expansion train with intermediate heating, 4 centrifugal pumps, 1 Pelton turbine (hydraulic turbine), air/water tanks and hot water tanks.

During off-peak load hours, the excess electrical energy available on the grid is used to compress air from the ambient pressure to the storage pressure which is about 120 bars. The compression process is achieved by 3 compressors. A heat exchanger is installed after each compressor to cool down the exiting hot air by water. The hot water is then stored in thermally insulated tanks under pressure (around 30 bars). During peak load hours, the compressed air is expanded in 3 turbines to release the stored energy. The compressed air is heated before each stage of expansion through heat exchangers using the stored hot water.

The air is stored under fixed pressure in the air/water tanks. The stored pressure is maintained constant through a counter-hydraulic pressure by varying the water volume during the storage and the destocking phases. Therefore, a Pelton turbine is installed at the water outlet of the storage tanks to recover the potential energy from the compressed water during the storage phase and a pump is also installed for pumping water into the tanks during the production phase and then keeping a constant storage pressure. The consumed energy during the storage phase is then the difference between the energy consumed by the compressors and the energy produced by the Pelton turbine, the produced energy during the production phase is the difference between the energy produced by the air turbines and the energy consumed by the pump. Air and water are separated by a piston.

Hot water is stored under a pressure of 30 bars to prevent water evaporation. The pressure is maintained constant by a counter-hydraulic pressure. A piston separates the hot water from the cold water.

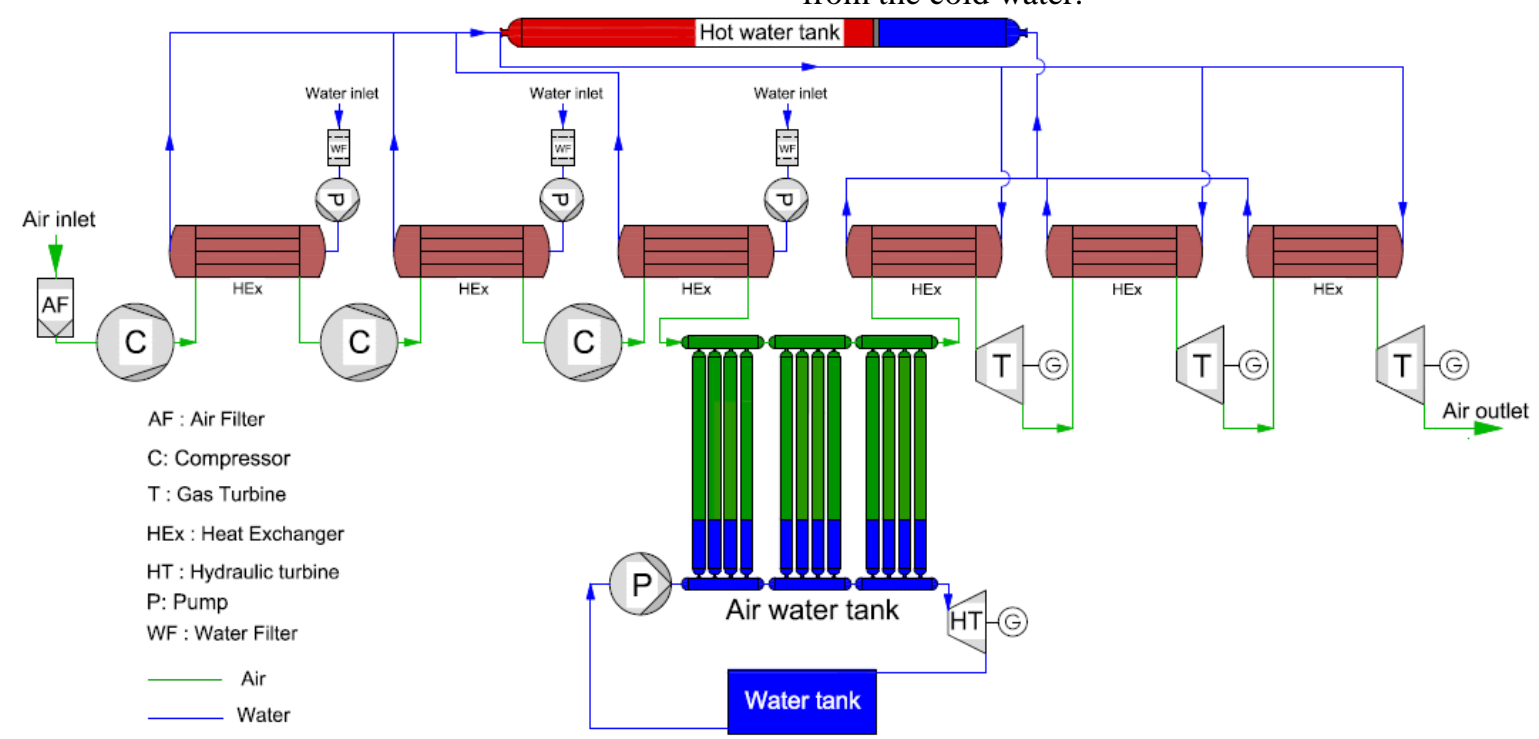

Figure 1. Schematic diagram of the proposed IA-CAES system. 


\section{Energy and Exergy Relations}

The exergy analysis based on the second law of thermodynamics takes into account the quantity and the quality of energy in any real process. Unlike the energy analysis based on the first law of thermodynamics, the exergy is not conserved during any real process due to irreversibilities. Consequently, the exergy analysis of a system including several forms of energy such as the proposed storage system (mechanical, thermal, electrical and potential) is necessary. In the proposed storage system, the chemical exergy is negligible because of the absence of the chemical reactions, then the total exergy is the physical exergy which is defined as [12]:

$$
E x=\dot{m}\left(h-h_{a}-T_{a}\left(s-s_{a}\right)\right)
$$

The exergy destruction of a component is the difference between the exergy resource and the exergy recovered. The thermodynamic equations and the exergy destruction within the different components of the storage system are presented in Table 1 .

All the transient phases in the storage cycle are neglected and only the steady states are modeled. The kinetic and potential effects are negligible. The isentropic and hydraulic efficiencies of the compressors, turbines and pumps are fixed. And all the components operate without heat loss.

The modeling is carried out using the software "Dymola" [13]. The modeling language "Modelica" of Dymola software is an object oriented language. It is a modeling language, rather than a conventional programming language. The associated simulator allows the resolution of the equations system at each time step. This software includes several fluid libraries among which water and air [14], [15] will be used.

The global model of the storage system is divided into subsystems which represent the components of the IA-CAES system. Every subsystem encloses the conservation laws of mass and energy and the exergy destruction computation. The components are connected with each other by the fluid properties (pressure and enthalpy) and the fluid mass flow rate.

The pressure loss in the heat exchangers is given as a parameter (fixed value) and it is neglected in the air/water and hot water tanks. The inlet enthalpy of the hot water tanks is the average of the inlet enthalpies of hot water weighted by the mass flow rate.

The exergy introduced into a storage tank corresponds to the case when no energy loss is occurring in the tank (heat and pressure losses). The recovered exergy is obtained after the deduction of all losses.

The efficiency of the IA-CAES system is given by Eq. (2). It is defined by the ratio of the energy produced during the destocking phase to the energy consumed during the storage phase since the system operates in two distinct phases over time

$$
\eta_{\text {net }}=\frac{E_{\text {Air_Turbines }}-E_{\text {pump }}}{E_{\text {Compressors }}-E_{\text {Hydraulic_Turbines }}+E_{C P}}
$$

where " $C P$ " stands for the circulation pumps (corresponding to the heat exchangers).

The efficiency given by Eq. (2) presents both the energy and the exergy efficiencies. In fact, the electrical energies consumed or produced by the rotating machinery are pure exergies. The energy density presents the energy produced by a unit volume of the stored air and is given as

$$
E D=\frac{E_{\text {Turbines }}-E_{\text {pump }}}{V_{\text {Air }}}
$$

where " $V_{\text {Air }}$ " is the maximum volume of stored air.

\section{Exergoeconomic Analysis}

The exergoeconomic analysis is a thermoeconomic study that combines the exergy analysis and the economic principles of a thermodynamic system. It helps the designers

\begin{tabular}{|c|c|c|}
\hline Subsystem & Energy relations & Exergy destruction \\
\hline Compressor & $h_{\text {out }}=h_{\text {in }}+\frac{h_{\text {ise }}-h_{\text {in }}}{\eta_{\text {ise }}} ; P_{\text {elec }}=\dot{m} \frac{h_{\text {out }}-h_{\text {in }}}{\eta_{\text {elec }}}$ (polytropic) & $\begin{array}{l}E x_{D}=P_{\text {elec }}-\Delta E x= \\
P_{\text {elec }}-\left(E x_{\text {out }}-E x_{\text {in }}\right)\end{array}$ \\
\hline Air turbine & $h_{\text {out }}=h_{\text {in }}-\eta_{\text {ise }}\left(h_{\text {in }}-h_{\text {ise }}\right) ; P_{\text {elec }}=\dot{m} . \eta_{\text {elec }} .\left(h_{\text {out }}-h_{\text {in }}\right)$ (polytropic) & $E x_{D}=P_{\text {elec }}-\Delta E x$ \\
\hline Pump & $h_{\text {out }}=h_{\text {in }}+\frac{h_{i s o}-h_{i n}}{\eta_{\text {hyd }}} ; P_{\text {elec }}=\dot{m} \frac{h_{\text {out }}-h_{\text {in }}}{\eta_{\text {elec }}}$ (isothermal process) & $E x_{D}=P_{\text {elec }}-\Delta E x$ \\
\hline Hydraulic turbine & $h_{\text {out }}=h_{\text {in }}-\eta_{\text {hyd }}\left(h_{\text {in }}-h_{\text {iso }}\right) ; P_{\text {elec }}=\dot{m} \cdot \eta_{\text {elec }} \cdot\left(h_{\text {out }}-h_{\text {in }}\right)($ isothermal $)$ & $E x_{D}=P_{\text {elec }}-\Delta E x$ \\
\hline $\begin{array}{l}\text { Heating heat } \\
\text { exchanger }\end{array}$ & $\begin{array}{c}\dot{m}_{\text {water }} C_{p_{\text {_water }}}=\dot{m}_{\text {air }} C_{p_{\text {_air }}} ; T_{\text {water_out }}=T_{\text {air_in }}+\Delta T_{\text {Pinch }} ; \\
\dot{m}_{\text {water }}\left|h_{\text {water_out }}-h_{\text {water_in }}\right|=\dot{m}_{\text {air }}\left|h_{\text {air_out }}-h_{\text {air_in }}\right|\end{array}$ & $E x_{D}=-\left(\Delta E x_{H o t}+\Delta E x_{C o l d}\right)$ \\
\hline $\begin{array}{l}\text { Cooling heat } \\
\text { exchanger }\end{array}$ & $\begin{array}{c}\dot{m}_{\text {water }} C_{p_{-} \text {water }}=\dot{m}_{\text {air }} C_{p_{-} \text {air }} ; T_{\text {air_out }}=T_{\text {water_in }}+\Delta T_{\text {Pinch }} ; \\
\dot{m}_{\text {water }}\left|h_{\text {water_out }}-h_{\text {water_in }}\right|=\dot{m}_{\text {air }}\left|h_{\text {air_out }}-h_{\text {air_in }}\right|\end{array}$ & $E x_{D}=-\left(\Delta E x_{H o t}+\Delta E x_{\text {Cold }}\right)$ \\
\hline Air/water tanks & $\frac{\dot{m}_{\text {water }}}{\rho_{\text {water }}}+\frac{\dot{m}_{\text {air }}}{\rho_{\text {air }}}=0$ & $E x_{D}=E x_{I d}-E x_{\mathrm{Re}}$ \\
\hline Hot water tanks & $M_{\text {water }} \cdot\left(h_{\text {in }}-h_{\text {out }}\right)=M_{\text {steel }} \cdot C_{p_{-} \text {steel }} \cdot \Delta T_{\text {steel }}$ & $E x_{D}=E x_{I d}-E x_{\mathrm{Re}}$ \\
\hline
\end{tabular}
to optimize the design and the operation of the considered

Table 1. Thermodynamic and exergy destruction relations for the components of the IA-CAES system.

(where " $\Delta T_{\text {Pinch" }}$ is the pinch and " $\Delta T_{\text {steel }}$ "is the steel's temperature variation between beginning and end of the storage phase.) 
system in a cost effective way. Thus the purpose of the exergoeconomic analysis is multiple:

- Evaluate the cost of production of each component;

- Explicit the flow of costs in the system;

- And find the optimum variables in a subsystem or the overall system by fixing an objective function [16].

Among the different exergoeconomic approaches existing in the literature, the SPECO approach [10] is used in this paper. It allows the definition of the auxiliary equations and the computation of the costs associated to the output exergy streams of each component by the fuel and product principles. Therefore, the fuels and products should first be defined for each component.

The fuel is defined by the resources required to generate the products such as the excess electrical energy consumed by the compressors in the proposed storage system. The product is defined by the desired results generated by the system or the subsystem such as the electrical energy produced by the air turbines [17].

In the exergoeconomic analysis below, the physical exergy will be divided into mechanical exergy and thermal exergy in order to improve the computation accuracy of the system where the pressure losses are not negligible [10]. This division allows calculating separately the cost rates of the mechanical and thermal exergies which are evaluated by

$$
\begin{aligned}
& \operatorname{Ex}^{M}(T, p)=h\left(T_{a}, p\right)-h\left(T_{a}, p_{a}\right)-T_{a}\left(s\left(T_{a}, p\right)-s\left(T_{a}, p_{a}\right)\right) \\
& \operatorname{Ex}^{T}(T, p)=h(T, p)-h\left(T_{a}, p\right)-T_{a}\left(s(T, p)-s\left(T_{a}, p\right)\right)
\end{aligned}
$$

Therefore, the fuels and products of the components of the IA-CAES system are defined in Table 2 based on the fuel $(\mathrm{F})$ and product $(\mathrm{P})$ principles of the SPECO approach. The product of the cooling heat exchanger is the hot water (thermal exergy only) because its purpose is to recuperate the compression heat in order to be reused during the production phase, and then the product of the heating heat exchanger is the compressed air (thermal exergy only) which will be expanded through the turbines to produce electricity. Thus, the product of the hot water tanks is the thermal exergy of hot water used to reheat the compressed air, and that of the air/water tanks is the mechanical exergy of the stored air.

The cost balance equation of a component, which receives a heat power $q$ (Fuel $F$ ) and produces a power $P$ (product $P o$ ), is given by

$$
\sum_{\text {out }} \dot{C}_{\text {out }}+\dot{C}_{P o}=\dot{C}_{F}+\sum_{\text {in }} \dot{C}_{\text {in }}+\dot{Z}
$$

where $\dot{Z}$ represents the amortization cost rate due to the capital investment and the operating and maintenance costs of the considered component. The cost rate $\dot{Z}$ is expressed as follows [18], [19]

$$
\dot{Z}=Z . C R F . \phi /(3600 * N)
$$

The maintenance factor " $\phi$ " is supposed equal to 1.06 [18], the number of system operating hours in a year " $N "$ is equal to $6205 \mathrm{~h}(17 \mathrm{~h} /$ day*365 days) and the capital recovery factor " $C R F$ " is defined by:

$$
C F R=\frac{i(1+i)^{n}}{(1+i)^{n}-1}
$$

The interest rate " $i$ " in the above equation is supposed equal to $10 \%$ [18] and the system life " $n "$ is equal to 20 years. The capital investments $Z$ of the components of the IA-CAES system are given in Table 3 according to [18] and [20].

The equation of the hydraulic turbine is inspired from that of the air turbine. The exponential term is neglected because the expansion process of water is always isothermal. The

\begin{tabular}{|c|c|c|}
\hline Components & Fuel & Product \\
\hline Compressor & $P_{\text {elec }}$ & $\left(E x_{\text {out }}^{T}-E x_{\text {in }}^{T}\right)+\left(E x_{\text {out }}^{M}-E x_{\text {in }}^{M}\right)$ \\
\hline Air turbine & $\left(E x_{\text {in }}^{T}-E x_{\text {out }}^{T}\right)+\left(E x_{\text {in }}^{M}-E x_{\text {out }}^{M}\right)$ & $P_{\text {elec }}$ \\
\hline Pump & $P_{\text {elec }}$ & $E x_{\text {out }}^{M}-E x_{\text {in }}^{M}$ \\
\hline Hydraulic turbine & $E x_{\text {in }}^{M_{1}-E x^{M}{ }_{\text {out }}}$ & $P_{\text {elec }}$ \\
\hline Cooling heat exchanger & 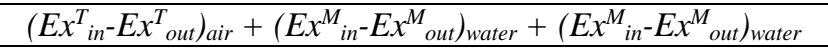 & $\left(E x_{\text {out }}^{T}-E x_{\text {in }}^{T}\right)_{\text {water }}$ \\
\hline Heating heat exchanger & 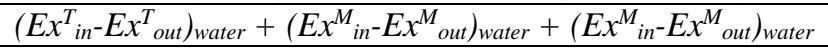 & $\left(E x_{\text {out }}^{T}-E x_{\text {in }}^{T}\right)_{\text {air }}$ \\
\hline Air/water tanks & 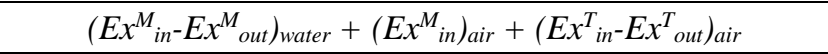 & $\left(E x^{M}{ }_{\text {out }}\right)_{\text {air }}$ \\
\hline Hot water tanks & $\left(\sum E x_{\text {in }}^{M_{1}}-\sum E x_{\text {out }}^{M}\right)+\sum E x_{\text {in }}^{T}$ & $\sum E x_{\text {out }}^{T}$ \\
\hline
\end{tabular}
maximum hydraulic turbine efficiency is assumed to be $94 \%$ (supplier data). The coefficients in the capital investment equations $Z$ are calculated based on real data supplied by the

Table 2. Definitions of the exergies of fuels and products for the components of the IA-CAES system.

Table 3. Capital investments for the components of the IA-CAES system.

\begin{tabular}{|c|c|c|}
\hline Compressor & $Z=\frac{C_{1} \dot{m}_{\text {air }}}{0.9-\eta_{\text {ise }}}\left(\frac{p_{\text {out }}}{p_{\text {in }}}\right) \ln \left(\frac{p_{\text {out }}}{p_{\text {in }}}\right)$ & $C_{1}=218$ \\
\hline Air turbine & $Z=\frac{C_{2} \dot{m}_{\text {air }}}{0.92-\eta_{\text {ise }}} \ln \left(\frac{p_{\text {in }}}{p_{\text {out }}}\right)\left(1+\exp \left(0.036 T_{\text {in }}-54.4\right)\right)$ & $C_{2}=896$ \\
\hline Pump & $Z=C_{3} \cdot P_{\text {elec }}^{0.71}$ & $C_{3}=50$ \\
\hline Hydraulic turbine & $Z=\frac{C_{4} \dot{m}_{\text {water }}}{0.94-\eta_{\text {hyd }}} \ln \left(\frac{p_{\text {in }}}{p_{\text {out }}}\right)$ & $C_{4}=13.5$ \\
\hline Heat exchanger & $Z=C_{5} \cdot A^{0.78}$ & $C_{C}^{B P}=1242 ; C_{C}^{M P}=1216 ; C_{C}^{H P}=584$ \\
\end{tabular}


manufacturers to evaluate the real purchase cost of the components.

Regarding the purchase costs of the air storage tanks and the hot water tanks (steel pipes), they are calculated as a function of the storage volume and the storage pressure (function of the materials resistance). The purchase costs of the tanks' accessories are also included.

The cost balance equation and the auxiliary equations of each component of the storage system are given in Table 4. The air and water inlet values of the air/water tanks should be multiplied by the mass flow rates ratio to be equivalent to the output values. The thermal exergy of water is negligible, and water is supposed to be the fuel in the tanks because the purpose of using this fluid is to deliver compressed air at a fixed pressure. The thermal and mechanical average costs (ratio of the cost rate over the exergy) of all outputs of the hot water tanks are equal respectively. In addition, the output mechanical average cost is equal to the arithmetic average cost of the input mechanical exergies. Finally, the consumed average power cost of the pump used to maintain a constant pressure in the air/water tanks is defined by

$c_{\text {Fuel }}^{\text {Pump }}=\frac{1}{3} \sum_{k}\left(\frac{\dot{C}_{P}}{E x_{\text {out }}-E x_{\text {in }}}\right)_{k}^{\text {Turbines }}$

The objective function used to optimize the overall system represents the sum of the electricity cost, consumed during the storage phase, and the amortization cost rate of all the components of the storage system [20]. It is defined as
ObjectiveFunction $=\left(c_{\text {Fuel }}\right)_{\text {Compressors }} *$

$\left(\left(P_{\text {elec }}\right)_{\text {Compressors }}-\left(\left(P_{\text {elec }}\right)_{\text {HydraulicTurbine }}\right)\right)+\sum_{k} \dot{Z}_{k}$

The exergoeconomic model is then integrated into the thermodynamic model and the optimization is performed using OmOptim, a genetic algorithm based optimizer. The decision variables selected for the optimization are the isentropic and hydraulic efficiencies of the rotating machines and the pinch of the heat exchangers. The objective function, which represents the cost of the product of the overall system, should be minimized in the conditions of the constrains given by the mathematical model of the system composed of energetic, exergetic balances and economical and constructive correlations and specific thermal and physical properties of the system.

\section{Simulation Results}

The operating parameters of the base case are given in Table 5 and Table 6 and the electrical efficiency of the rotating machines is supposed equal to $96 \%$ (data supplied by the suppliers). The storage phase and production phase durations are $12 \mathrm{~h}$ and $5 \mathrm{~h}$ respectively and the output power produced during the production phase is $100 \mathrm{MW}$. The cost of electricity (fuel cost) in France is equal to $0.1114 € / \mathrm{kWh}$ $\left(c_{\text {Fuel,compressors }}\right)$. The ambient pressure and temperature are considered equal to 1.01325 bars and $25^{\circ} \mathrm{C}$ respectively.

Table 4 Cost balance equations and corresponding auxiliary equations for each component of the IA-CAES system.

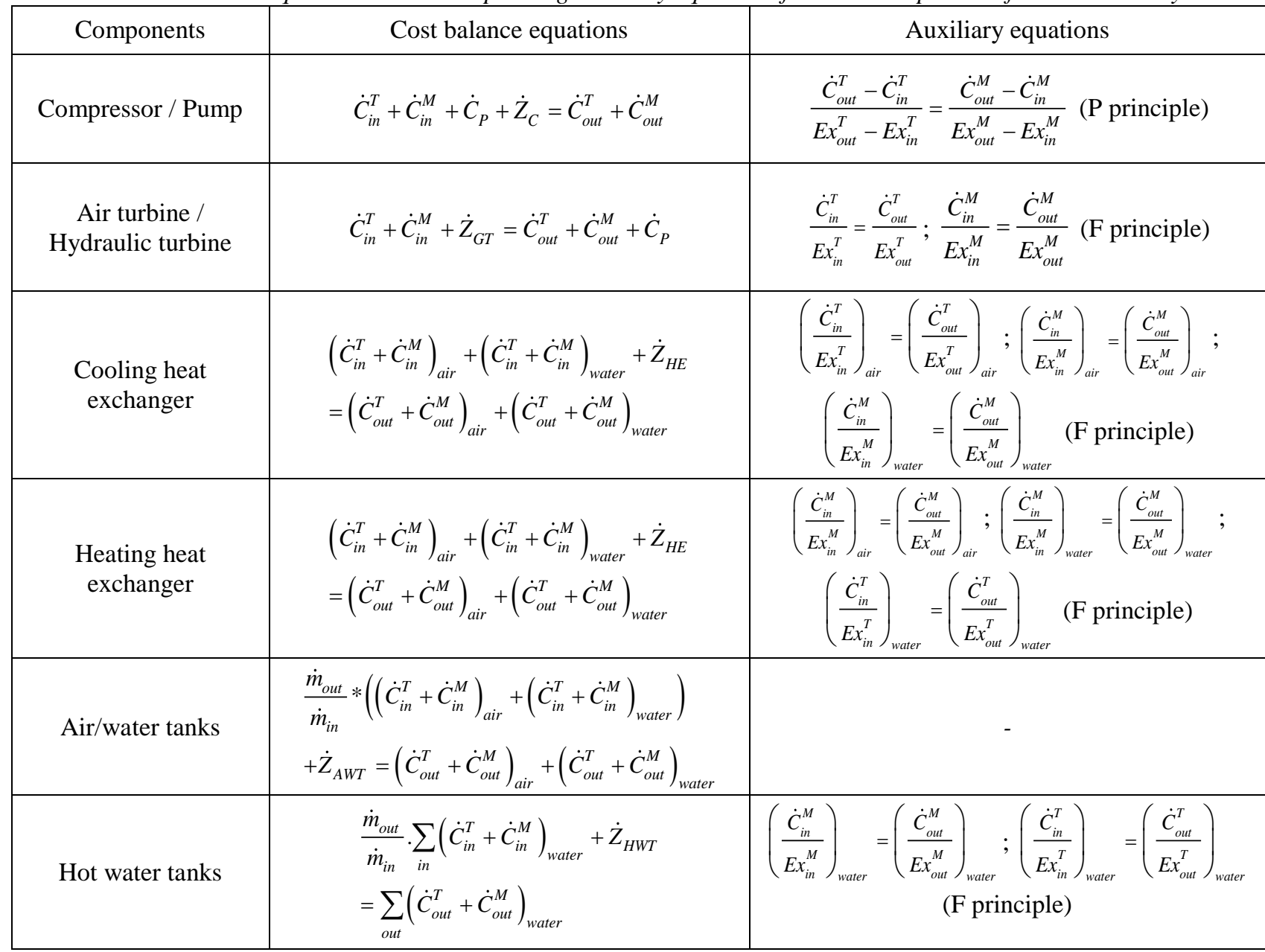


Table 5: Pressure losses in the heat exchangers.

\begin{tabular}{|l|c|c|c|}
\hline Pressure losses (bars) & LP & MP & HP \\
\hline Cooling heat exchanger & 0.1719 & 0.1346 & 0.0287 \\
\hline Heating heat exchanger & 0.1125 & 0.3345 & 0.876 \\
\hline
\end{tabular}

The simulations show that the efficiency of the system is about $55.1 \%$ and the energy density is $11.9 \mathrm{kWh} / \mathrm{m}^{3}$. The air/water tanks constitute $44 \%$ of the total investment cost of the system (sum of $\dot{Z}$ ). Therefore, increasing the energy density has a positive effect on the total purchase cost. It leads to reduce the volume of the air storage tanks, which have the major investment cost, and then to decrease the total purchase cost. The optimization launched to increase the energy density and the efficiency at the same time gives the curve of Figure 2. It shows that the energy density is inversely proportional to the system efficiency. The exergoeconomic analysis is then essential to find an optimal solution between the efficiency and the investment cost; this is achieved by minimizing the objective function using a genetic algorithm. This function takes into account the system efficiency (by including the fuel cost) and the investment cost (by including the sum of $\dot{Z}$ ). To start the optimization, the admissible range of the compressors isentropic efficiency is set between $75 \%$ and $90 \%$ and that of the turbines between $75 \%$ and $92 \%$, the hydraulic efficiency of the pump and the hydraulic turbine between $0.75 \%$ and $0.94 \%$, and the pinch of the heat exchangers between $5 \mathrm{~K}$ and $20 \mathrm{~K}$.

The optimization results are given in Table 6 which compares the base case with the optimum case. The objective function value is $3.5 € / \mathrm{s}$ in the base case. It is reduced by $3.7 \%$ after optimization, the fuel cost by $2.8 \%$ and the investment cost by $5.6 \%$. However, the efficiency is increased by $2.7 \%$ and the energy density by $6.7 \%$. Furthermore, the average unit cost of electricity produced by the air turbines, which was $0.3166 € / \mathrm{kWh}$, is reduced by $5.5 \%$.

The distribution of the exergy destruction costs is given in Figure 3. The exergy destruction cost of a component is evaluated by Eq. (11) where the fuel cost $c_{F, k}$ of the $k^{\text {th }}$ component is given by Eq. (12).

$$
\begin{aligned}
& \dot{C}_{e x, D, k}=c_{F, k} \cdot E x_{D, k} \\
& c_{F, k}=\left(\frac{\dot{C}_{o u t, F}-\dot{C}_{i n, F}}{E x_{o u t, F}-E x_{i n, F}}\right)_{k}
\end{aligned}
$$

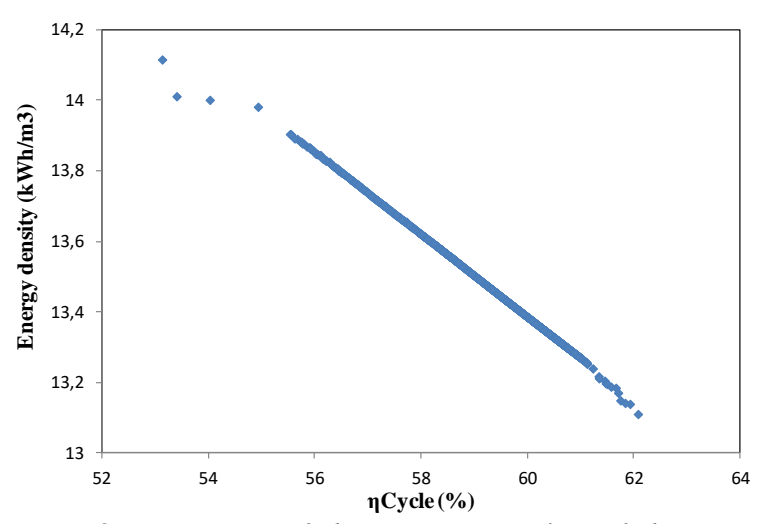

Figure 2. Variation of the optimum value of the energy density as a function of the system efficiency.

Figure 3 shows that the highest exergy destruction cost occurs in the air turbines. The turbines efficiency and the air admission temperatures of these turbines should then be increased to reduce the exergy destruction. The second highest exergy destruction cost occurs in the heating heat exchangers. Therefore, the compressors efficiency and the pinch of the cooling heat exchangers are decreased in the optimization case in order to improve the thermal storage exergy. The pinch of the heating heat exchangers is also reduced and the turbines efficiency is improved. Consequently, the exergy destruction costs in the turbines and the heating heat exchangers are decreased.

Sensitivity analyses of the efficiencies of the rotating machines and the pinch of the heat exchangers are carried out to examine the effects of these parameters on the system efficiency and the objective function. The analyses are performed by fixing the objective parameters to be analyzed at the desired values and then launching the optimization to minimize the objective function by varying the other decision variables. The results are shown in Figure 4, Figure 5, Figure 6 and Figure 7.

\begin{tabular}{|c|c|c|c|c|c|}
\hline \multirow[t]{2}{*}{$e^{-1}$} & Base case & Optimum case & & \multicolumn{2}{|r|}{ Optimum case } \\
\hline & \multicolumn{2}{|c|}{$\eta_{\text {ise }}(\%)$} & & \multicolumn{2}{|c|}{$\eta_{\text {ise }}(\%)$} \\
\hline LP compressor & 87 & 85,11 & LP turbine & 87 & 87,98 \\
\hline MP compressor & 87 & 84,87 & MP turbine & 87 & 88,14 \\
\hline \multirow[t]{2}{*}{ HP compressor } & 87 & 85,34 & HP turbine & 87 & 87,94 \\
\hline & \multicolumn{2}{|c|}{$\eta_{\text {hyd }}(\%)$} & & \multicolumn{2}{|c|}{$\eta_{\text {hyd }}(\%)$} \\
\hline \multirow[t]{2}{*}{ Pump } & 92 & 94 & Hydraulic turbine & 92 & 90,76 \\
\hline & \multicolumn{2}{|c|}{ Pinch $(\mathrm{K})$} & & \multicolumn{2}{|c|}{ Pinch $(\mathrm{K})$} \\
\hline LP cooling HEx & 10 & 5 & LP heating HEx & 10 & 5 \\
\hline MP cooling HEx & 10 & 5 & MP heating HEx & 10 & 5 \\
\hline \multirow[t]{2}{*}{ HP cooling HEx } & 10 & 5 & HP heating HEx & 10 & 5 \\
\hline & \multicolumn{2}{|c|}{$\eta_{\text {net }}(\%)$} & & \multicolumn{2}{|c|}{$(\boldsymbol{E} / \mathrm{h})$} \\
\hline \multirow[t]{2}{*}{ net efficiency } & 55,1 & 56,6 & Objective function & 12600 & 12128,4 \\
\hline & \multicolumn{2}{|c|}{$(\mathrm{kWh} / \mathrm{m3})$} & Fuel cost & 8398,8 & 8164,8 \\
\hline Energy density & 11,878 & 12,674 & Investment cost & 4201,2 & 3967,2 \\
\hline
\end{tabular}

Table 6. Comparison of the optimization parameters and the main results between the base case and the optimal case. 


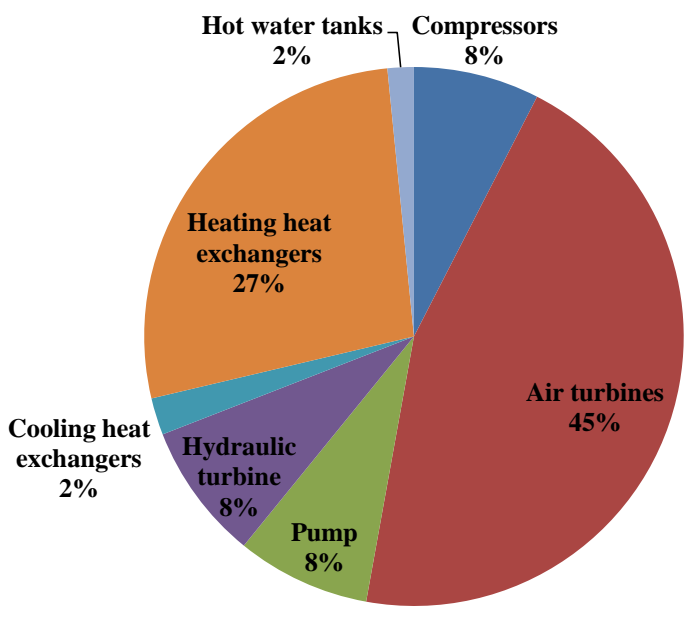

Figure 3. Distribution of the exergy destruction costs among the storage system components.

The variations of the system efficiency are almost linear in all the cases. The results show that the highest slope of the efficiency curves is that of Figure 4. Thus the system efficiency is mostly sensitive to the air turbines efficiency, with the slope value being $8.2 \% / 10 \%$ (the system efficiency increases $8.2 \%$ every $10 \%$ of improvement of the turbines efficiency). However, the increase of the turbines efficiency will be limited by the purchase cost of these machines. The objective function starts to increase when the turbines efficiency becomes higher than approximately $88 \%$.

The second highest slope of the system efficiency is that of Figure 5 and is about $4.9 \% / 10 \%$. The compressors efficiency should be limited between $80 \%$ and $85 \%$ to prevent the increase of the objective function for two reasons: first by the raise of the purchase cost of these machines and second by the reduction of the exergy quality of the stored hot water.

The slope of the efficiency curve in Figure 6 is $2.9 \% / 10 \mathrm{~K}$ (the efficiency increases $2.9 \%$ every $10 \mathrm{~K}$ of decrease of the pinch of the heat exchangers). The figure shows that the objective function always decreases with the enhancement of the pinch. Therefore, the optimum value of this variable should be set to $5 \mathrm{~K}$ (the minimum value) for all the heat exchangers.

Regarding the hydraulic turbine, the slope of the efficiency curve is $0.5 \% / 10 \%$ (Figure 7 ). The objective function decreases slightly with the turbine efficiency enhancement. Then an optimum value of about $91 \%$ is selected by taking into account the purchase cost constraint.

Finally, the slope associated to the pump efficiency is $2.9 \% / 10 \%$. Thus the pump efficiency enhancement is contributing positively to the system efficiency. The maximum efficiency of the pump is limited to $94 \%$ due to the investment cost constraint and the technological limitations.

The sensitivity analyses prove that the isentropic efficiency of the air turbines is the most influential factor for the system efficiency and the objective function. Furthermore, the enhancement of the air turbines efficiency, the air inlet temperatures of the air turbines and the pump efficiency help to increase the energy density and thus compact the capacity of the several components of the storage system and especially the volume of the air storage tanks.

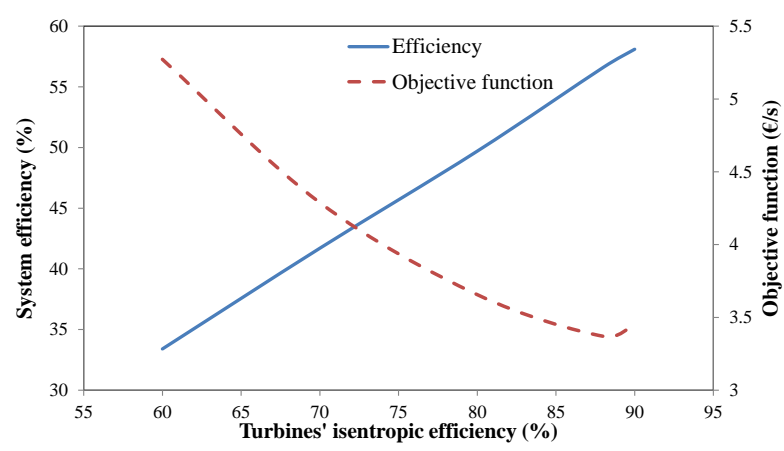

Figure 4. Sensitivity of the system efficiency and the objective function to the air turbines efficiency.

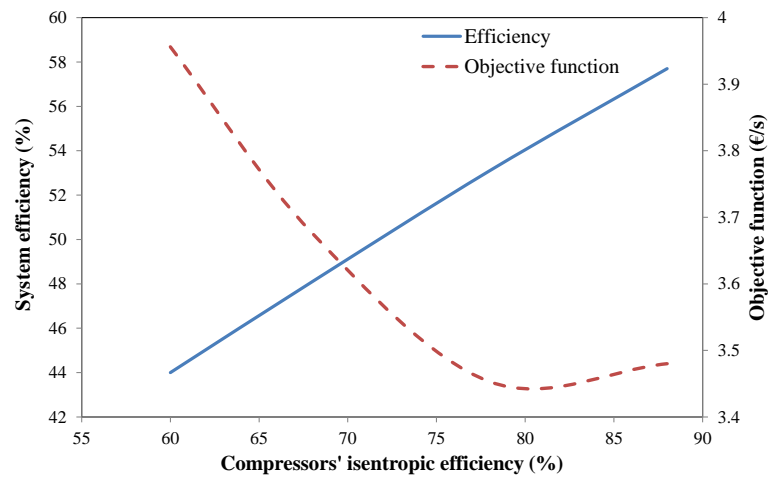

Figure 5. Sensitivity of the system efficiency and the objective function to the compressors efficiency.

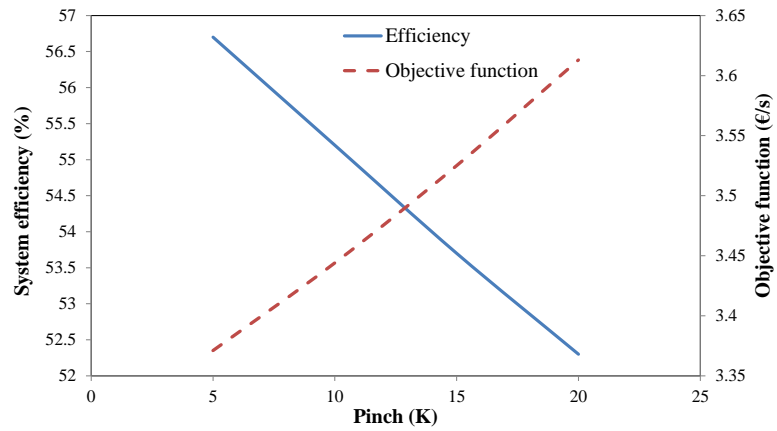

Figure 6. Sensitivity of the system efficiency and the objective function to the pinch of heat exchangers.

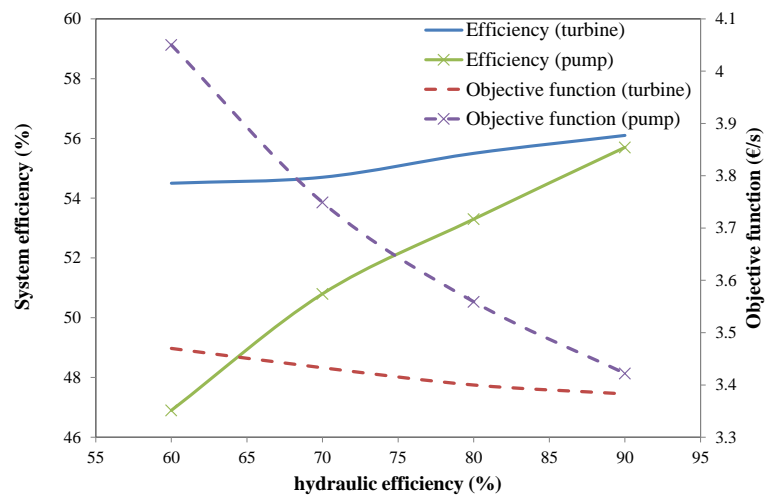

Figure 7. Sensitivity of the system efficiency and the objective function to the hydraulic efficiencies.

\section{Conclusions}

The growing integration of the renewable energy sources into the electrical grid requires energy storage systems. Thus, a novel isobaric adiabatic compressed air energy storage 
system is proposed in this paper. Exergy and exergoeconomic analyses are then conducted to improve the cost-effectiveness of the storage system. The exergoeconomic model is achieved by the SPECO approach. The exergy analysis shows that the system efficiency is $55.1 \%$ and the energy density is $11.9 \mathrm{kWh} / \mathrm{m}^{3}$. The exergoeconomic analysis illustrates high exergy destruction costs in the air turbines and the heating heat exchangers. An optimization using genetic algorithm is then conducted and leads to improve the efficiency by $2.7 \%$ and the energy density by $6.7 \%$. This is achieved by reducing the objective function, (including fuel, investment, operating and maintenance costs) by $3.7 \%$.

Finally, sensitivity analyses are carried out and show that the cost-effectiveness of the storage system is more sensitive to the air turbines efficiency than the other parameters. In addition, the analyses show that the efficiencies of the rotating machines should be improved by taking into account the economic constraints. Regarding the heat exchangers, the pinch should be reduced to its minimum value because it costs less than the enhancement of the rotating machines' efficiencies.

\section{Nomenclature}

\begin{tabular}{|c|c|}
\hline$A$ & Area, $\left(\mathrm{m}^{2}\right)$ \\
\hline$c$ & Average cost rate, $(€ / J)$ \\
\hline CAES & Compressed air energy storage \\
\hline$C_{p}$ & Specific heat capacity, (J/kg.K) \\
\hline$C R F$ & Capital recovery factor \\
\hline$D T$ & Temperature difference, $\left({ }^{\circ} \mathrm{C}\right)$ \\
\hline$E$ & Energy, $(\mathrm{J})$ \\
\hline$E D$ & Energy density, (kWh/m3) \\
\hline$E x$ & Exergy, (W) \\
\hline$E x^{M}$ & Mechanical exergy, (W) \\
\hline$E x^{T}$ & Thermal exergy, (W) \\
\hline$h$ & Mass enthalpy, $(\mathrm{kJ} / \mathrm{kg})$ \\
\hline HP & High pressure \\
\hline$i$ & Interest rate, $(\%)$ \\
\hline IA-CAES & $\begin{array}{l}\text { Isobaric adiabatic compressed air energy } \\
\text { storage }\end{array}$ \\
\hline LP & Low pressure \\
\hline$M$ & Mass, $(\mathrm{Kg})$ \\
\hline MP & Medium pressure \\
\hline$N$ & $\begin{array}{l}\text { Number of system operating hours in a } \\
\text { year, (years) }\end{array}$ \\
\hline$n$ & System life , (years) \\
\hline$P$ & Power, (W) \\
\hline$p$ & Pressure, $(\mathrm{Pa})$ \\
\hline PHS & Pumped hydro storage \\
\hline$s$ & Entropy, (W/K) \\
\hline SPECO & Specific exergy costing \\
\hline $\mathrm{T}$ & Temperature, $\left({ }^{\circ} \mathrm{C}\right)$ \\
\hline $\mathrm{V}$ & Volume, (m3) \\
\hline $\mathrm{Z}$ & Purchase cost of the components, $(€)$ \\
\hline
\end{tabular}

$$
\begin{array}{ll}
\dot{C} & \text { Stream cost, }(€ / \mathrm{s}) \\
\dot{m} & \text { Mass flow rate, }(\mathrm{kg} / \mathrm{s}) \\
\dot{Z} & \text { Cost rate of the components, }(€ / \mathrm{s})
\end{array}
$$

Greek symbols

$$
\begin{array}{ll}
h & \text { Efficiency, } \% \\
\rho & \text { Density, }(\mathrm{Kg} / \mathrm{m} 3) \\
\Delta & \text { Difference between input and output } \\
\phi & \text { Maintenance factor }
\end{array}
$$

Subscripts

$\begin{array}{ll}a & \text { Ambient } \\ C & \text { Cooling heat exchanger } \\ \text { cycle } & \text { Cycle of the studied storage system } \\ D & \text { Destruction } \\ \text { elec } & \text { Electric } \\ \text { ex } & \text { Exergetic } \\ H & \text { Heating heat exchanger } \\ F & \text { Fuel } \\ \text { hyd } & \text { Hydraulic } \\ \text { Id } & \text { Ideal } \\ \text { in } & \text { Input } \\ \text { ise } & \text { Isentropic } \\ \text { iso } & \text { Isothermal } \\ \text { out } & \text { Output } \\ \text { Po } & \text { Product } \\ \text { Re } & \text { Real }\end{array}$

\section{References:}

[1] S. K. Khaitan and M. Raju, "Dynamic simulation of air storage-based gas turbine plants," Int. J. Energy Res., 37, 558-569, 2013.

[2] C. Bullough, C. Gatzen, C. Jakiel, M. Koller, A. Nowi and S. Zunft, "Advanced adiabatic compressed air energy storage for the integration of wind energy," Proceedings of the European Wind Energy Conference, EWEC 2004, London UK, 8, 22-25 November 2004.

[3] H. Safaei and D. Keityh, ", DW. Keityh, "Compressed air energy storage with waste heat export: An Alberta case study," Energy Convers. Management, 78, 114124, 2014.

[4] M. Saadat, F. A. Shirazi and P. Y. Li, "Modeling and control of an open accumulator Compressed Air Energy Storage (CAES) system for wind turbines," Applied Energy, 137, 603-616, 2015.

[5] L. Nielsen and R. Leithner, "Dynamic simulation of an innovative compressed air energy storage plant Detailed modeling of the storage cavern," WSEAS Transactions on Power Systems, 4, 253-263, August 2009.

[6] P. Zhao, J. Wang and Y. Dai, "Thermodynamic analysis of an integrated energy system based on compressed air energy storage (CAES) system and 
Kalina cycle," Energy conversion managment, 98, 161-172, 2015.

[7] Y. MAZLOUM, H. Sayah and M. Nemer, "Static and dynamic modeling comparison of an adiabatic compressed air energy storage system," Journal of Energy Resources Technology, 138, 8, November 2016.

[8] A. Dobrovicescu, "Exergoéconomie," Thermodynamique et énergétique, Technique de l'ingénieur, 17, 2014.

[9] A. Lazzaretto and G. Tsatsaronis, "Comparison between SPECO and functional exergoeconomic approaches," In: Proceedings of ASME international mechanical engineering congress and exposition. IMECE/AES-23656, New York, ASME, November 11$16 ; 2001$.

[10] A. Lazzaretto and G. Tsatsaronis, "SPECO: A systematic and general methodology for calculating efficiencies and costs in thermal systems," Energy, 31, 1257-1289, 2006.

[11] G. Cammarata, A. Fichera and L. Marletta, "Using genetic algorithms and the exergonomic approach to optimize district heating networks," ASME: Journal of Energy Resources Technology, 120, 241-246, 1998.

[12] Y. M. Kim, J.-- -H. Lee, S. J. Kim and D. Favrat, "Potential and Evolution of Compressed Air Energy Storage: Energy and Exergy Analyses," Entropy, 14, 1501-1521, 2012.

[13] Dassault systems, The official web site of Dymola, http://www.3ds.com/productsservices/catia/capabilities/modelica-systemssimulation-info/dymola.
[14] J. R. Cooper and R. B. Dooley, "The International Association for the Properties of Water and Steam," Lucerne, Switzerland, August 2007.

[15] B. J. McBride, M. J. Zehe and S. Gordon, "NASA Glenn Coefficients for Calculating Thermodynamic Properties of Individual Species," NASA report TP2002-211556, 2002.

[16] A. Abusoglu and M. Kanoglu, "Exergetic and thermoeconomic analyses of diesel engine powered cogeneration: Part 1 - Formulations," Applied Thermal Engineering, 29, 234-241, 2009.

[17] A. Baghernejad and M. Yaghoubi, "Exergoeconomic analysis and optimization of an Integrated Solar Combined Cycle System (ISCCS) using genetic algorithm," Energy Conversion and Management, 52, 2193-2203, 2011.

[18] N. Shokati, F. Mohammadkhani, M. Yari, S. M. S. Mahmoudi and M. A. Rosen, "A Comparative Exergoeconomic Analysis of Waste Heat Recovery from a Gas Turbine-Modular Helium Reactor via Organic Rankine Cycles," Sustainability, 6, 24742489, 2014.

[19] F. Mohammadkhani, S. Khalilarya and I. Mirzaee, "Exergy and exergoeconomic analysis and optimization of diesel engine based Combined Heat and Power (CHP) system using genetic algorithm," Int. J. Exergy, 12, 139-161, 2013.

[20] A. Valero, M. A. Lozana, L. Serra, G. Tsatsaronis, J. Pisa, C. Frangopoulos and M. R. Von Spakovsky, "CGAM problem : definition and conventional solution," Energy, 19, 279-286, 1994. 